\title{
PEMANFAATAN DIRECTION API (APPLICATION PROGRAMMING INTERFACE) PADA LAYANAN GOOGLE MAP UNTUK PENCARIAN RUMAH IBADAH DI KOTAMADYA YOGYAKARTA PADA HANDPHONE BERBASIS ANDROID
}

\author{
Gunawan Addiwinoto, Hero Wintolo, Dwi Nugraheny \\ Teknik Informatika STTA Yogyakarta \\ informatika@stta.ac.id
}

\begin{abstract}
Since the smartphone android as open technology was found, the Users can take some advantages from Google's map service which is exist in the application to build the applications service. API direction can using HTTP to determine the location of the inter-view destination, mileage and road routes that can be passed either as a text string or as a latitude or longitude that can be implemented through a Google map.

By using this direction google map service, API, can be used this service to create a searching application service to search the houses of worship. Besides used for knowing generally the houses of worship that exist around the Yogyakarta city, the determination of the shortest path is needed because in this life people often travel from one place to another by considering the efficiency of time, mileage and expenses.

Searching service of the houses of worship is existed in the application, it can be tested in various service providers through the internet and GPS signal strength which is optimal enough to obtain the shortest distance with the direction on the map and with a percentage accuracy of the average distance between Google on the map with the actual distance of $99 \%$.
\end{abstract}

Keywords: HTTP, Google map, Direction API, GPS.

\section{Abstrak}

Adanya android sebagai teknologi smartphone yang open source, user bisa memanfaatkan layanan Google map yang terdapat pada aplikasi untuk membangun layanan aplikasi. Direction API dapat memanfaatkan HTTP untuk menentukan arah antar lokasi dangan tujuan, jarak tempuh dan rute jalan yang bisa dilalui baik sebagai string teks atau sebagai lintang atau bujur yang bisa diimplementasikan melalui Google map.

Pemanfaatan direction API pada layanan gogle map ini, bisa dimanfaatkan untuk membangun layanan aplikasi pencarian rumah ibadah. Selain mengetahui secara umum rumah ibadah yang ada di sekitar wilayah Kotamadya Yogyakarta, dalam hal pencarian rumah ibadah, penentuan jalur terpendek sangat diperlukan karna di dalam kehidupan kita sering melakukan perjalanan dari satu tempat ke tempat yang lain dengan mempertimbangkan efisiensi waktu, jarak tempuh dan biaya.

Pencarian rumah ibadah yang terdapat pada aplikasi, dapat diujikan dengan berbagai provider melalui layanan internet dan kekuatan sinyal GPS yang cukup optimal untuk mendapatkan jarak terpendek dengan hasil direction pada map dengan persentase keakuratan jarak tempuh rata-rata antara Google pada map dengan jarak sebenarnya 99 \% . 


\section{Kata kunci : HTTP, Google map, Direction API, GPS.}

\section{Pendahuluan}

Android adalah software pada mobile device yang meliputi sistem operasi yang digunakan pada smartphone yang dirilis Google yang salah satu komponennya Android Standart Development Kid (SDK) yang menyediakan perlengkapan dan Application Programming Interface (API) yang diperlukan untuk memulai pengembangan aplikasi pada platform android menggunakan bahasa pemrograman Java, yaitu file yang ditandai dengan ekstensi .apk lalu didistribusikan sebagai aplikasi dan diinstal pada perangkat mobile berbasis android. Salah satu layanan yang diakses dengan peralatan ini adalah Google map dengan API sebagai salah satu fungsi yang ada di dalam Google map.

API merupakan kepanjangan Application Programming Interface yang merupakan interface (sarana atau media dari dua sistem yang terpisah untuk berkomunikasi) yang mengimplementasikan aplikasi yang memungkinkan aplikasi lain untuk berkomunikasi dengannya. Direction API merupakan layanan yang menghitung arah antara lokasi menggunakan permintaan HTTP.

Penentuan jalur terpendek diperlukan karna di dalam kehidupan kita sering melakukan perjalanan dari satu tempat ke tempat yang lain dengan mempertimbangkan efisiensi waktu, jarak tempuh dan biaya Dengan tampilan layar berbasis web browser yang lebih banyak dimanfaatkan untuk peta dan rute jalan dan juga bisa dimanfaatkan untuk membangun layanan aplikasi dengan memanfaatkan informasi peta. Selain itu Google map juga memberikan informasi tentang rute yang akan dilalui dalam bentuk teks.

\section{Google Map}

Google map adalah layanan peta secara online yang disediakan oleh Google dalam bentuk tampilan peta yang dimanfaatkan secara gratis dengan memanfaatkan teknologi foto satelit sehingga dapat melihat bagaimana landscape planet bumi.Fasilitas yang ada pada Google map antara lain adalah menjelajah peta, mencari lokasi tertentu, seperti hotel, restoran, dan menghitung rute dalam berkendara Google map dibuat menggunakan kombinasi dari gambar peta, database, serta objek-objek interaktif yang dibuat dengan bahasa pemrograman HTML, javascript dan bahasa pemrograman lainnya.

\section{Direction API}

Google Direction API merupakan layanan untuk menentukan arah antar lokasi dangan memanfaatkan HTTP. Arah antar lokasi antara lain tempat dimana pengguna berada, tempat yang akan dituju, atau koordinat penentu latitude (garis lintang) dan longitude (garis bujur). Directions API dapat mengembalikan beberapa directions dengan menggunakan satu garis titik lokasi (waypoints). Pengguna directions API dibatasi untuk 2.500 titik permintaan dengan 8 titik directions per hari dan juga directions URL dibatasi 2.048 karakter. 


\section{Perancangan}

\subsection{Kebutuhan Perangkat Lunak}

Kebutuhan perangkat lunak yang digunakan adalah $J d k$-6u16-windows-i586.exe sebagai Java compiler di sistem personal computer berbasis windows, Eclipse-jee-indigo-SR1-win32 dimana Eclipse merupakan Java platform editor untuk pengembangan program berbasis Java. Platform tambahan lainnya berupa android-SDK_r16-windows berfungsi sebagai software development kit platform tambahan pemrograman berbasis Java, ADT-16.0.1 emulator android sebagai development tool kit android emulator built in Eclipse. Pengujian dilakukan pada handphone dengan spesifikasi telah tertanam GPS dan telah tertanam android Operating System. Dalam melakukan pencarian rumah ibadah berdasarkan Google map dengan mendapatkan koordinat posisi longitude dan latitude.

\subsection{Perancangan Antarmuka}

Perancangan antarmuka aplikasi digunakan oleh user diimplementasikan melalui handphone. Pada perancangan aplikasi prayer place untuk user terdiri dari tampilan awal Prayer Place, input data dan view lokasi. Pada tampilan awal menu Prayer Place terdiri dari tempat ibadah masjid, gereja kristen, gereja katholik, pura dan vihara, sedangkan pada bagian input data dan view data terdiri dari nama, alamat, keterangan, kategori, foto, longitude dan latitude.

\begin{tabular}{|c|c|c|}
\hline & Prayer Place & \\
\hline & Masjid & \\
\hline & Jereja Kristen & \\
\hline & ereja Katholik & \\
\hline & Pura & \\
\hline Tambah Lokasi & Cari Lokasi & Exit \\
\hline
\end{tabular}

Gambar 1. Rancangan tampilan prayer place

\section{Pengujian dan Analisa}

\subsection{Penjelasan Aplikasi}

Bagian terpenting dari aplikasi ini adalah pemanfaatan Direction API ( Application Programming Interface) antara 2 tempat yang harus bebas dari kesalahan yang mungkin terjadi seperti validitas dan keakuratan posisi point yang di dapat dari GPS (Global Positioning System) yang sudah tertanam di handphone android. Pemanfaatan GPS dilakukan untuk mengetahui posisi user yaitu koordinat longitude (garis lintang) dan latitude (garis bujur).

Tampilan awal menu Prayer Place terdiri dari masjid, gereja kristen, gereja katholik, pura dan vihara yang berupa tampilan list dan terdapat beberapa elemen pendukung. Elemen ini digunakan untuk mendukung user dalam melakukan fungsi tambahan yang terdiri dari menu tambah lokasi yang berfungsi untuk melakukan input data dan juga terdapat menu cari lokasi 
yang digunakan untuk mengetahui detail (view data) dari rumah ibadah yang diinginkan berupa alamat rumah ibadah maupun koordinat longitude dan latitude. Tampilan layanan input data yang terdapat pada menu tambah lokasi. Sebagai sample, user akan melakukan penambahan data melalui layanan input data rumah ibadah agama hindu yang terdapat di wilayah Kotamadya Yogyakarta, yaitu rumah ibadah Pura Citra Buana Saraswati melalui menu tambah lokasi.

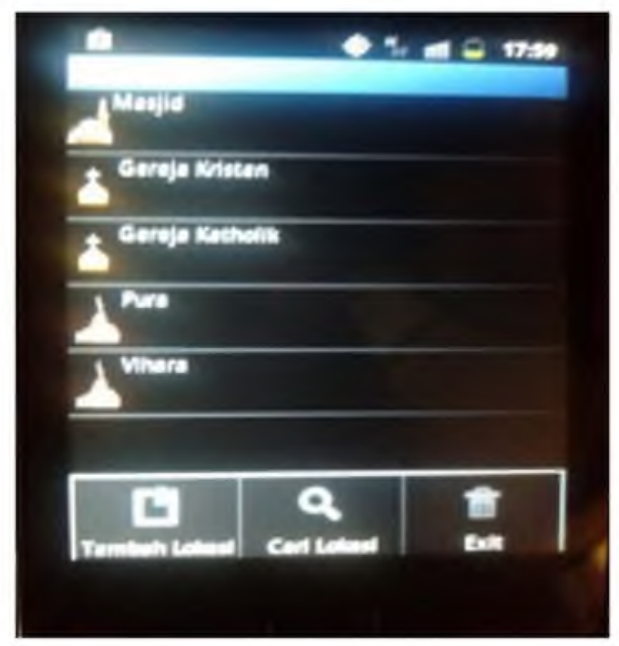

Gambar 2. Menu Prayer Place

Di dalam melakukan input data diperlukan data koordinat longitude dan latitude, user bisa mendapatkan data koordinat secara manual dengan berada langsung dengan lokasi yang akan dijadikan sample. Dengan mengaktifkan layanan GPS yang telah tersedia pada handphone maka hasil koordinat yang didapatkan setelah berada di lokasi Pura Citra Buana Saraswati adalah longitude $=110.383791$ dan latitude $=-7.793540$. Setelah itu user memasukkan data yang ingin dimasukkan ke dalam layanan tampilan input data rumah ibadah aplikasi Prayer Place seperti pada gambar 3 .

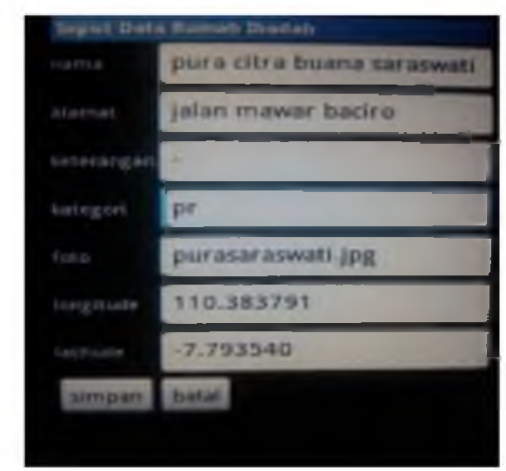

Gambar 3. Tampilan Input data

Setelah user menginputkan data yang telah tersimpan di dalam database, user bisa memastikan data yang diinputkan bisa ditampilkan pada map, user kembali ke tampilan awal menu aplikasi Prayer Place. Setelah itu user memilih menu pura yang ada di tampilan list lalu memilih pura yang telah diinputkan dan marker pura akan terlihat pada titik geopoint map yang menunjukkan bahwa data pura yang diimputkan sebelumnya telah tertampil dalam map. 


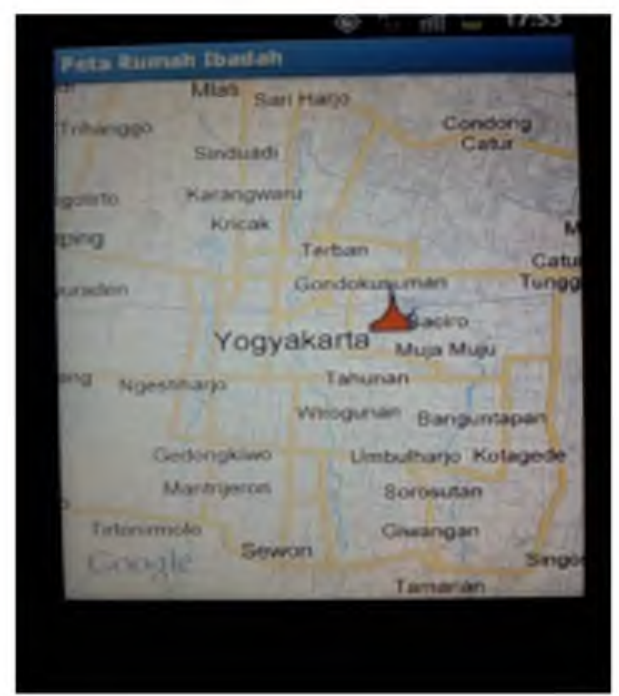

Gambar 4. Marker pura pada Map

Untuk memanfaatkan direction API yang akan digunakan dalam mencari jalur terpendek, user berada pada koordinat longitude $=110.377468$ dan latitude $=-7.780156$, yaitu cafe SS sagan dan terlebih dahulu user harus mengaktifkan GPS lalu user menyentuh marker pura yang ada pada map dan user akan mendapatkan informasi jarak terdekat seperti pada gambar 5.

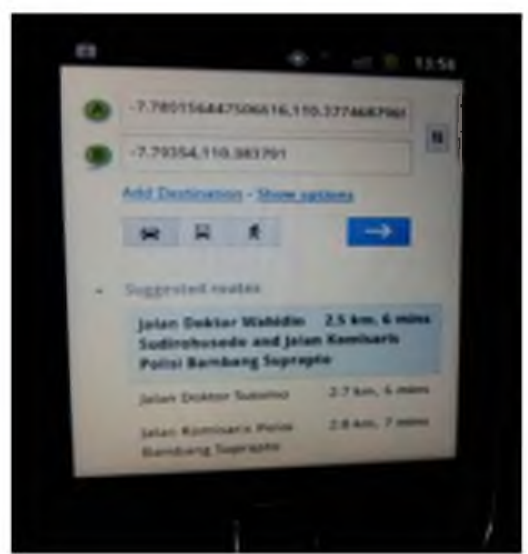

Gambar 5. Informasi Jarak terdekat

Pada gambar 6, penentuan direction yang dilakukan pada koordinat longitude = 110.377468 dan latitude $=-7.780156$ seperti pada gambar 5 menuju koordinat longitude $=$ 110.383791 dan latitude $=-7.793540$ Pura Citra Buana Saraswati, diketahui bahwa jarak terdekat yang didapatkan melalui Jalan Doktor Wahidin Sudirohusodo dan Jalan Komisaris Polisi Bambang Suprapto dengan jarak tempuh 2,5 km. 


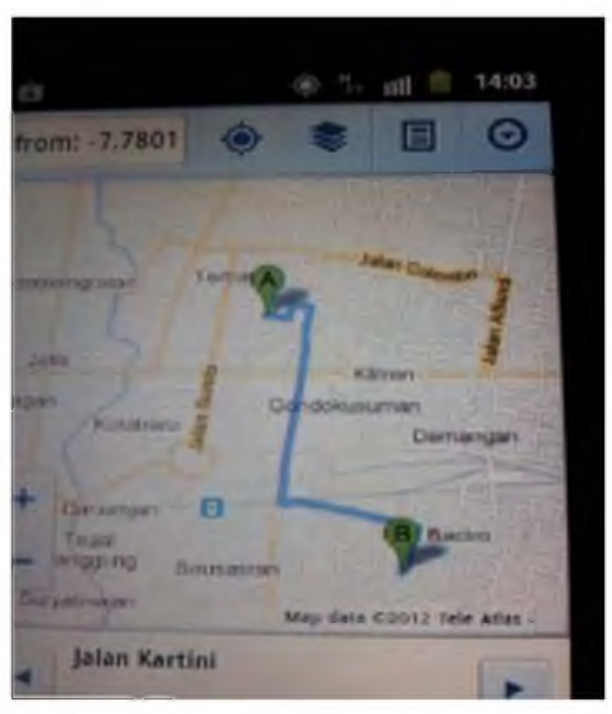

Gambar 6. Direction terdekat

User mendapatkan informasi seperti pada gambar 3.5 yang menunjukkan jalur terdekat yang harus dilalui dari posisi user berada (marker A) ke posisi tujuan Pura Citra Buana Saraswati (marker B). Jarak tersebut lebih pendek dibandingkan jika user harus melalui Jalan Doktor Sutomo dengan jarak tempuh 2,7 km atau Jalan Komisaris Polisi Bambang Suprapto dengan jarak tempuh $2,8 \mathrm{~km}$ seperti pada gambar 3.4. Untuk menguji keakuratan jarak yang didapatkan Google pada map, user melakukan pengujian dengan menggunakan speedometer sepeda.

\subsection{Uji Provider}

Pengujian aplikasi dilakukan secara bergantian menggunakan 7 provider resmi dengan menggunakan 1 handphone Samsung Galaxy Y. Uji provider dilakukan untuk mengetahui biaya yang dikeluarkan dalam mendapatkan jalur terpendek pencarian rumah ibadah pada aplikasi Prayer Place melalui internet seperti pada tabel 1.

Tabel 1. Uji coba Provider

\begin{tabular}{|c|c|cc|}
\hline No & Provider & \multicolumn{2}{|c|}{ Biaya } \\
\hline 1 & Simpati & Rp & $352,-$ \\
\hline 2 & As & Rp & $256,-$ \\
\hline 3 & Mentari & $R p$ & $192,-$ \\
\hline 4 & M3 & Rp & $153,-$ \\
\hline 5 & Axis & Rp & $820,-$ \\
\hline 6 & XL & Rp & $1000,-$ \\
\hline 7 & Tri & Rp & $710,-$ \\
\hline
\end{tabular}

Pada tabel 1 diketahui bahwa biaya yang dikeluarkan untuk mendapatkan jalur terpendek dengan mengakses aplikasi Prayer Place melalui internet berbeda-beda pada masing-masing provider. 


\subsection{Uji Fungsi}

Pengujian dilakukan untuk mendapatkan keakuratan data dengan membandingkan jarak yang didapatkan Google pada map dengan jarak sebenarnya yang dilakukan dengan menggunakan speedometer sepeda dengan mengikuti hasil direction pada map seperti yang ada pada gambar 6. Penghitungan jarak dilakukan dari titik A yaitu cafe SS Sagan menuju titik B yaitu Pura Citra Buana Saraswati yang melalui 3 direction rekomendasi Google berdasarkan jarak tempuh yang dihasilkan masing-masing direction seperti pada tabel .2.

\begin{tabular}{|l|l|l|l|l|l|}
\hline \multicolumn{6}{|c|}{ Tabel 2. Hasil Jarak antara Google map dan Jarak sebenarnya } \\
\hline 1 & $\begin{array}{l}\text { Nura Citra Buana } \\
\text { Saraswati melalui Jalan } \\
\text { Doktor Wahidin } \\
\text { Sudirohusodo }\end{array}$ & 110.383791 & -7.793540 & $2.5 \mathrm{~km}$ & $\begin{array}{l}\text { Jarak } \\
\text { sebenarnya }\end{array}$ \\
\hline 2 & $\begin{array}{l}\text { Pura Citra Buana } \\
\text { Saraswati melalui Jalan } \\
\text { Doktor Sutomo }\end{array}$ & 110.383791 & -7.793540 & $2.7 \mathrm{~km}$ & $2.65 \mathrm{~km}$ \\
\hline 3 & $\begin{array}{l}\text { Pura Citra Buana } \\
\text { Saraswati melalui Jalan } \\
\text { Kompol Bambang } \\
\text { Suprapto }\end{array}$ & 110.383791 & -7.793540 & $2.8 \mathrm{~km}$ & $2.76 \mathrm{~km}$ \\
\hline
\end{tabular}

Keakuratan antara hasil jarak tempuh dari Google pada map dengan jarak yang sebenarnya dapat dihitung dalam persentase dengan rumus sebagai berikut:

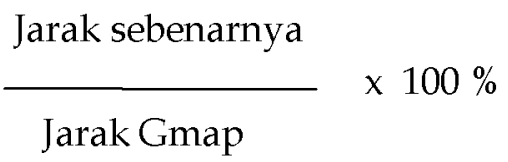

Berdasarkan rumus menghitung persentase diatas, user dapat menghitung keakuratan antara hasil jarak tempuh yang dihasilkan dari Google pada map dengan jarak sebenarnya menggunakan speedometer seperti pada tabel 3.3.

Tabel 3. Persentase keakuratan Jarak Gmap dan Jarak sebenarnya

\begin{tabular}{|c|l|c|}
\hline No & \multicolumn{1}{|c|}{ Nama Tujuan } & Persentase Keakuratan \\
\hline 1 & $\begin{array}{l}\text { Pura Citra Buana Saraswati melalui Jalan } \\
\text { Doktor Wahidin Sudirohusodo }\end{array}$ & $99,6 \%$ \\
\hline 2 & $\begin{array}{l}\text { Pura Citra Buana Saraswati melalui Jalan } \\
\text { Doktor Sutomo }\end{array}$ & $98,1 \%$ \\
\hline 3 & $\begin{array}{l}\text { Pura Citra Buana Saraswati melalui Jalan } \\
\text { Kompol Bambang Suprapto }\end{array}$ & $98,5 \%$ \\
\hline
\end{tabular}

Berdasarkan tabel 3, dapat disimpulkan bahwa keakuratan jarak tempuh antara Google pada map dengan jarak yang sebenanya berbeda-beda pada masing-masing jalur yang dilewati (direction). Keakuratan jarak tempuh antara Google pada map dengan jarak yang 
sebenarnya tidak mencapai $100 \%$. Validitas tertinggi antara Google pada map dengan jarak sebenarnya dalam menguji coba aplikasi Prayer Place untuk mencari jarak terpendek yaitu 99,6 \% melalui jalan Wahidin Sudirohusodo, sedangkan validitas terendah yaitu 98,1 \% melalui jalan Doktor Sutomo.

\section{Kesimpulan}

1. Aplikasi Prayer Place berbasis android smartphone dapat membantu user mendapatkan rumah ibadah di wilayah Kotamadya Yogyakarta dan dapat dikembangkan di sekitar luar wilayah Kotamadya Yogyakarta melalui layanan input data yaitu menu tambah lokasi pada aplikasi Prayer Place.

2. Persentase keakuratan jarak tempuh antara Google pada map dengan jarak sebenarnya menggunakan speedometer tidak mencapai $100 \%$.

3. Pencarian jarak terpendek yang dilakukan menggunakan direction API (Application Programming Interface) sangat ditentukan oleh kekuatan sinyal GPS pada masing-masing provider.

\section{Referensi}

[1] Fera Suprapti, Perancangan Web Franchise Pempek dan Mobile Monitoring Berbasis Android, Compiler, Volume 1 Nomor 1. Mei 2012.

[2] Firki, Rijalul, Adam, Fuadana, Ipam dan Prakoso, Iman., Pemrograman JAVA, Andi, Yogyakarta, Indonesia, 2005.

[3] Hermawan, Stephanus, Mudah Membuat Aplikasi Android, Penerbit Andi, Yogyakarta, Indonesia, 2011.

[4] Mulyadi, Membuat Aplikasi untuk Android, Multimedia Center Publishing, Yogyakarta, Indonesia, 2010.

[5] Sinaga, Benyamin L., Pemrograman Berorientasi Objek dengan JAVA, Gaya Media, Yogyakarta, Indonesia, 2004. 